\title{
Outreach facilities within a research center
}

\section{Zambon, G. Thériault, A.-S Poulin-Girard}

V. Zambon, G. Thériault, A.-S Poulin-Girard, "Outreach facilities within a research center," Proc. SPIE 8481, Optics Education and Outreach II, 848100 (15 October 2012); doi: 10.1117/12.929907

SPIE Event: SPIE Optical Engineering + Applications, 2012, San Diego, California, United States 


\title{
Outreach facilities within a research center
}

\author{
V. Zambon", G. Thériault and A.-S. Poulin-Girard \\ Center for Optics, Photonics and Lasers, Université Laval, Québec, Canada, G1V 0A6
}

\begin{abstract}
Worldwide, volunteers from student associations and non-profit organizations carry out outreach activities with high school students in their classrooms. Most of the time, these activities highlight optical phenomena but do not provide information about the reality of researchers in companies and universities. To address this issue, Université Laval's OSA and SPIE student chapters set up a demonstration laboratory dedicated to outreach, located in a research center. In this paper, we list the advantages of this type of facility as well as the steps leading to the creation of the laboratory, and we give an overview of the demonstration laboratory.

Keywords: outreach, demonstration laboratory, research center, holography
\end{abstract}

\section{INTRODUCTION}

Each year student volunteers from Université Laval's OSA and SPIE Student Chapters carry out outreach activities with over 350 high school students. When we go to the classrooms, students often ask about our day-to-day work and our work environment. It is easier to answer this question when they can actually see our environment, like during the Photonic Games, when more than 120 students come to our university to participate in optics challenges and take a laboratory tour [1]. During this tour, they are generally surprised about what they see, not having imagined it that way. Building on the success of the Photonic Games lab tour and requests from school groups to visit the research center, we decided to create a special laboratory within our research center, dedicated to outreach activities. The grand opening of the demonstration laboratory took place on October $29^{\text {th }}, 2010$.

This paper is divided into three sections. Section 2 delineates the advantages of this type of facility for visitors, graduate students and research centers. Section 3 details the different steps that lead to the creation of the demonstration laboratory and Section 4 presents an overview of the laboratory itself, and highlights plans for its future.

\section{ADVANTAGES OF THIS TYPE OF FACILITY}

The demonstration laboratory benefits all groups involved, especially the visitors from different backgrounds and the graduate students that are in charge of the creation, the maintenance and the activities of the lab. The host center and companies that sponsored the laboratory also profit from this facility.

\subsection{Visitors for whom science is not fiction anymore}

Most of the visitors to the demonstration laboratory are high school and college students that come with their teachers during planned visits. They meet graduate students in their working environment who give information about the work of researchers in optics and photonics, but also about the possibilities of studying in this field. The visitors gain practical skills, meaningful knowledge on light theory and valuable insight on careers in optics and photonics. The laboratory is a great learning tool for a wide variety of optics-related topics such as light propagation, diffraction, reflection, refraction, interference, photochemistry, etc. Finally, these visits help to break the image that many young students have of the lonely nerd scientist in his lab; the visitors get the opportunity to interact with university-level students in the field of photonics. They also get to see high-tech equipment that cannot be brought to their classrooms.

*veronique.zambon.1@ulaval.ca; phone 1-418-656-2131 ext. 16566; http://www.repol.copl.ulaval.ca/holographie/

Optics Education and Outreach II, edited by G. Groot Gregory, Proc. of SPIE Vol. 8481

$848100 \cdot$ (c) 2012 SPIE · CCC code: 0277-786/12/\$18 - doi: 10.1117/12.929907 
In 2010, more than 70 guidance counselors visited the demonstration laboratory during a special day of activities at the university. The comments that we received after the visit were very positive and the discussion about studies and careers in optics with the graduate student leading the activity was said to be instructive. In 2011, as a special activity, a visit to the demonstration lab was added to an undergraduate course entitled Practice of the Physics Engineer. Led by a graduate student, the undergrads visited the laboratory and were required to hand in a written review to their professor. The activity was a way to interest undergraduate students in our own university in pursuing of graduate studies in optics and photonics.

\subsection{A playground for graduate students}

The idea of creating this laboratory came from two graduate students who were curious about holography. Realizing the need of our student chapter for outreach facilities within our research center, they decided to build a holography laboratory dedicated to outreach activities with the help of our student chapter and our research center. This laboratory has really become our scientific hobby mostly because of the freedom that we enjoy regarding the content and the management of the laboratory.

The benefits for the graduate students who participated in the creation and the management of the demonstration laboratory are multiple because the process is similar to the task facing a new professor in setting up his or her laboratory. Starting with an empty room, we acquired concrete experience in building a research project from scratch. We had to show autonomy and organizational skills in determining the equipment that we needed, find financial partners, choose and buy the material, set up the laboratory, prepare the experimental protocols, and so forth. Since none of us had specific knowledge about holography, a lot of research and work was done to develop our collective expertise in this topic [2-3]. During the test-error phase, some of us showed unfailing perseverance and determination. Now that the setup is complete and functional, we have the responsibility to deal with problems that arise with the equipment and to make sure that the stock of consumables is maintained.

Since the demonstration laboratory is dedicated to outreach activities, posters have been designed to illustrate the different phenomena that are observed during the visits. These posters have to be versatile enough to be clear to different audiences, from high school students to guidance counselors and people from general public. Also, the visit has to be fun and suited to the audience. We have had to develop our communication and popularization skills to give the best visit possible. We have gained teaching experience through our interaction with the visiting groups.

\subsection{Our research center, a place for knowledge for everyone}

Our research center, the Center for Optics, Photonics and Lasers (COPL), has always received numerous inquiries from people wishing to visit the facilities. Sometimes visits involve just a few people, but other times, they can be for groups of more than 100 persons. It is easy to see how 100 visitors in the same day can inevitably disrupt ongoing research activities because of the noise and the traffic in the laboratories and in the corridors. However, the major problem was the dust control in the clean rooms section of the center. The clean room laboratories are not suited for large groups of visitors, and the experimental set-ups are rarely adapted for non-professionals or neophytes. The creation of a dedicated outreach facility in the "grey" section of the center settled all these problems. Some visits are still organized in other sections of the research laboratories but most of them take place in the demonstration laboratory. Since the creation of the laboratory, the research center can hold more visits, offer suitable activities to all groups and be better known in the community. The laboratory brings visibility to the research center by increasing awareness about optics and photonics.

\subsection{Partners in outreach and technology}

To this day, thirteen organizations and companies support the demonstration laboratory. Some of them donated equipment, like an optical table, and others are financial partners. Our partners understand the importance of outreach activities to make optics and photonics known to the general public and to encourage young students to pursue studies and careers in this field. With the hands-on optical demonstration laboratory, we want to spark the interest of high school students to study in optics. All our sponsors get visibility in the laboratory, on our web site and on documents related to the demonstration laboratory. 


\section{STEPS LEADING TO THE CREATION OF THE LAB}

The first thing we did when we had the idea to create this lab in the summer of 2009 was to organize a meeting with the Director of our research center, Professor Réal Vallée, because we needed the infrastructure inside the center to support the project. Prof. Vallée decided to help us in the creation of the lab. A laboratory room was reserved in the optics building for this purpose. The COPL also hired graduate students in optics to set the laboratory up and provided technical support for the project; a laboratory technician was available to help the students.

To set up the laboratory, we needed to purchase equipment and materials. We established a budget as well as a sponsorship plan to find funding. We worked on building partnerships with local industries and different organizations for this project. These companies donated some of the required materials or financed part of the project, and the names of the companies are displayed inside the laboratory and on our web site. We also applied for the SPIE grant of the LaserFest outreach program and earned a $\$ 6,700$ grant, which was our main support and really helped us to start up the project. We received a total of $\$ 14,000$ in financial support from SPIE, CorActive, INO, CIPI-S, Université Laval, Delta Photonics and CIPI. We also received equipment: optical tables (Exfo and Cégep Garneau), power meter (Gentec-EO) and laser safety glasses (Kentek, Sperian and NoIR Lasershields).

When we began to receive funding, we started to purchase the materials for the lab. First, we had to make a list of all the equipment we needed and found the best deals with different suppliers. We had to be well documented about the optical set-up we wanted to make.

The first optical demonstration we made was a holography set-up. We had to do many tests before obtaining our first hologram. We are still working on the best recipe to produce good quality holograms, but we already have satisfying results. We also built a Michelson interferometer to explain light interference.

We received our first visitors in October 2010. We are now working on developing other optical demonstrations and finding new ideas to popularize the science of light. With an important grant from the Canadian Institute for Photonic Innovations (CIPI), we will complete the laboratory with three other set-ups about adaptive optics, biophotonics and ultrafast laser applications.

\section{TOUR OF THE DEMONSTRATION LABORATORY}

As mentioned in section 2.2, the demonstration laboratory contains a holography set-up. It also contains a fiber-optics set-up, and we are planning to add three more demonstration set-ups for a total of five, each of them representing one of the research axes of the Center for Optics, Photonics and Lasers. The following sub-sections describe each of the set-ups that are already in the laboratory or will be installed soon. When the laboratory will be completed, a poster describing the underlying optics phenomena will accompany each experiment.

\subsection{Holography set-up}

The holography set-up is the first one to have been completed. This demonstration represents the research axis on Photonic materials. Even if our center does not lead research in the specific field of holography, we believe that it is an interesting demonstration for the visitors. We created a set-up to expose reflection holograms as shown in Fig. 1.

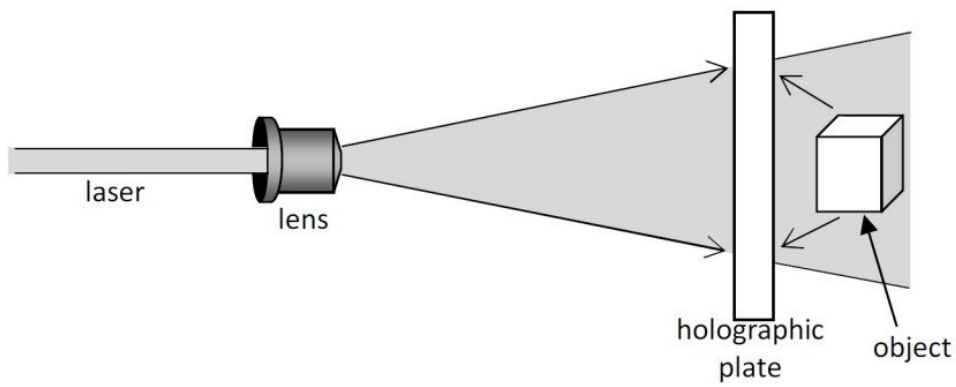

Figure 1. Schematic representation of the creation of reflection holograms 
The interference pattern between the reference beam and the reflected beam is registered on the holographic plate. Once developed by immersion in different chemicals, reflection holograms are easy to see with a white light. Figure 2 shows the optical set-up and Figure 3 shows various holograms.

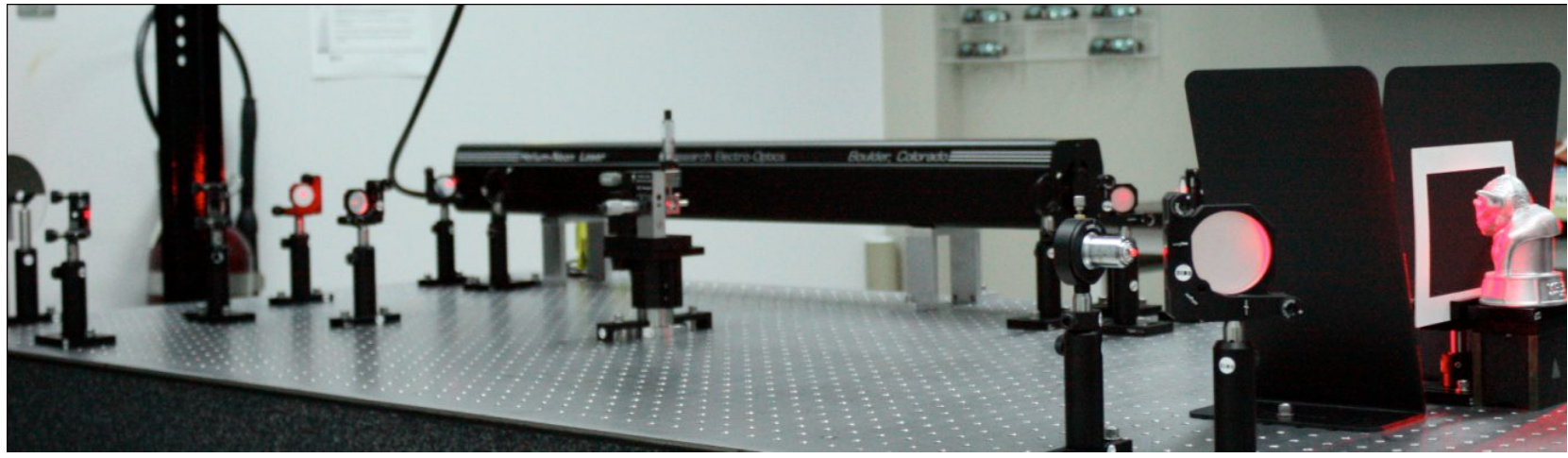

Figure 2. The $35 \mathrm{~mW}$ He-Ne laser beam is split, filtered and spread out to uniformly illuminate the object in this demonstration of how holograms are exposed. The black panels on the right block light from sideways illumination that could cause interference in the holographic plate.
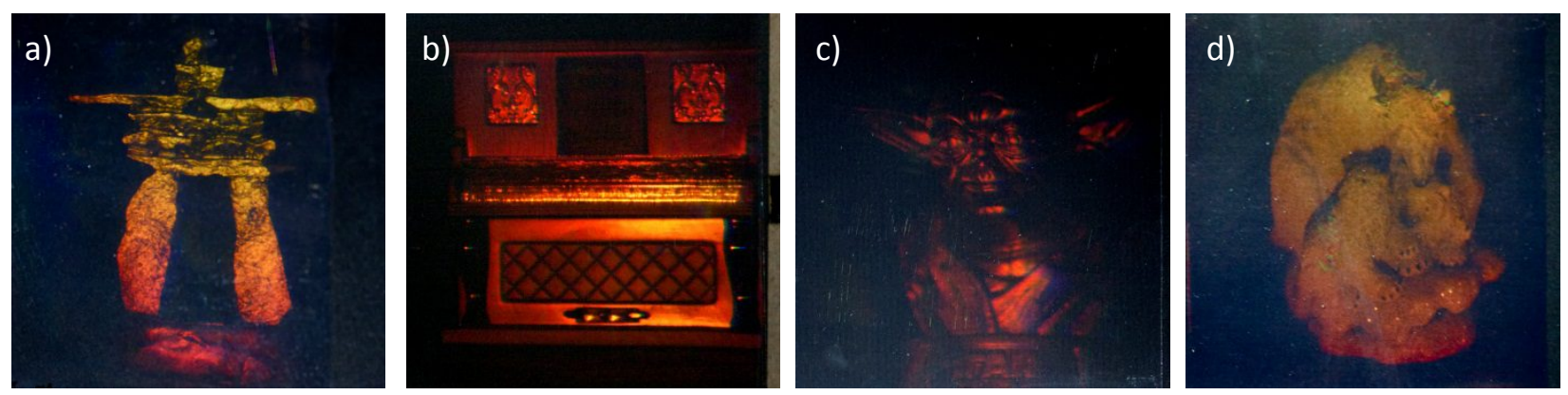

Figure 3. Holograms of a) Inukshuk, b) piano, c) Yoda and d) polar bears.

\subsection{Fiber optics set-up}

The fiber optics set-up is a courtesy of Professor Younès Messadeq and technician Steeve Morency, and it represents the research axes of Fiber-optics and guided-wave optics and Optical communications. It contains a curved Plexiglas stripe and a green laser to show total internal reflection, and a wireless communication system with a microphone and a speaker. It also includes an infrared laser, a piece of chalcogenide glass and an infrared detection card to illustrate the transmittance of infrared light in certain materials that look opaque to our eyes, as well as a glass preform with a Cobaltdoped core. All the components are shown in Figure 4. 


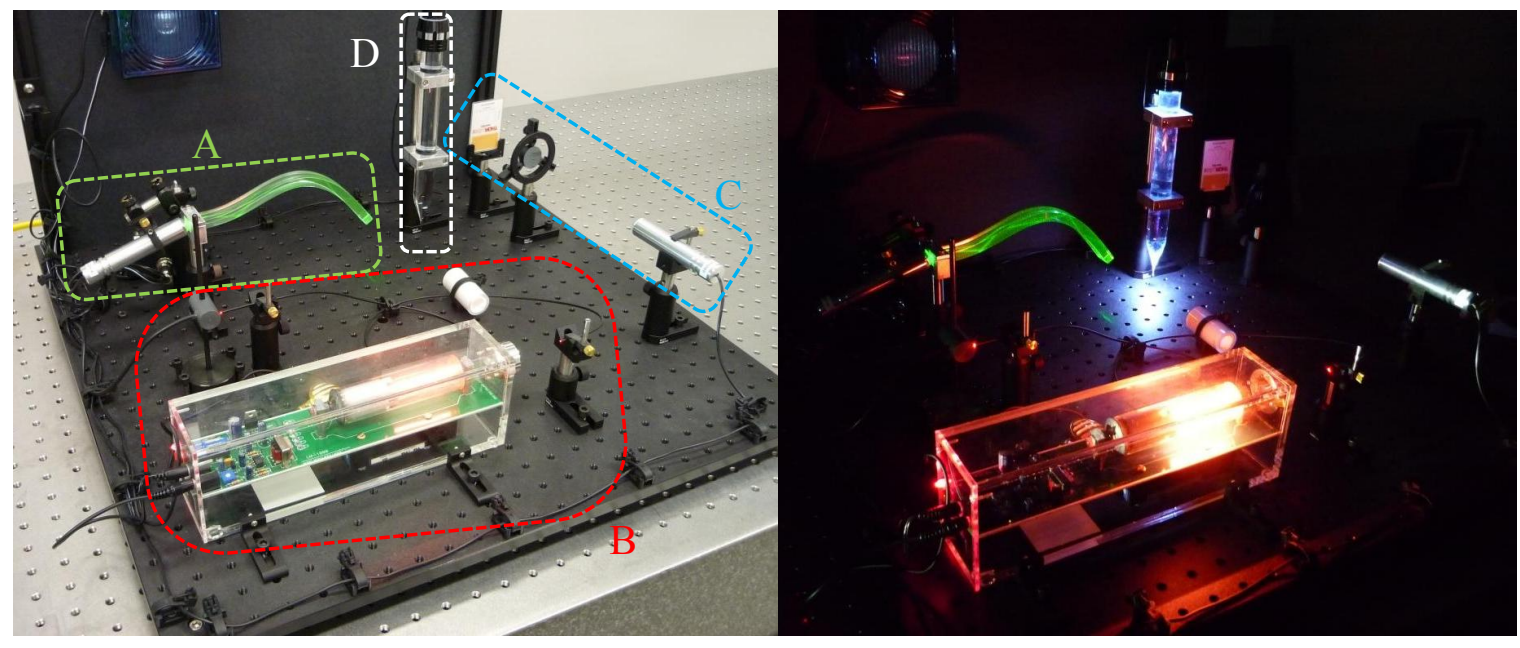

Figure 4. Fiber optics set-up showing total internal reflection (A), wireless communication (B), transmittance of materials (C) and a fiber optics pre-form (D).

The set-up also contains a schematic representation of the electromagnetic spectrum. We are planning to add a schematic about total internal reflection, a description of the working principle of wireless communication, information on fiber optics manufacturing and drawing towers, and explanations about the apparent transparency and opacity of materials.

One big advantage of this set-up is that it is portable. It is small and light enough to be moved by one person and be transported in a car so it can be used in a classroom or in a science fair for example.

\subsection{Adaptive optics set-up}

We are planning to add an adaptive optics set-up to illustrate the research axis on Optical engineering that will include a deformable mirror and a wave-front sensor. The adaptive optics set-up will give us the opportunity to introduce the concept of wave fronts. The goal of this set-up will be to show that modifications in the wave front can be corrected to recover a clear image of an object. In this case, it will be easy to link the experiment with real-life applications like telescopes and land-based wireless communication.

\subsection{Oxymeter set-up}

The Biophotonics axis regroups many researchers from the Center for Optics, Photonics and Lasers and from the Centre de recherche Université Laval Robert-Giffard. To represent this research axis, we would like to build an oxymeter (a non-invasive device that uses light to measure the level of oxygen in blood). Figure 5 shows a similar experiment that has already been built for an undergraduate laboratory and that will be easy to replicate.

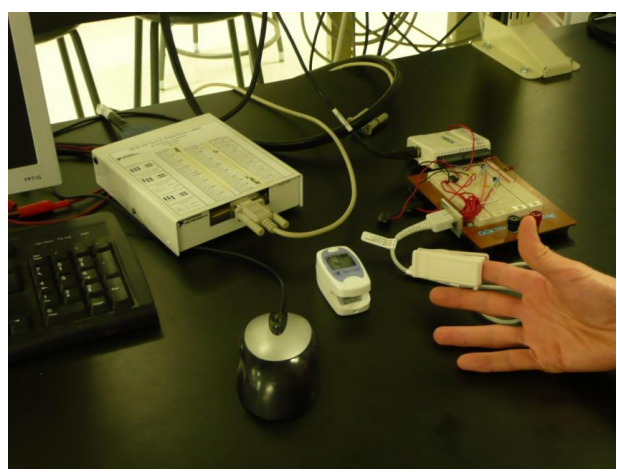

Figure 5. Oxymeter set-up as installed in an undergraduate teaching laboratory 
In addition, this set up will run with LabView, giving us the opportunity to introduce the visitors to this software and its possibilities.

\subsection{Laser cutting set-up}

It was hard to find a safe and affordable idea for an experiment to represent the research axis of Lasers and short pulses. One great idea that was suggested by one of our sponsors is to put a webcam in their company and be able to show, in real-time, the laser-cutting process. The images from the webcam would be projected on a white wall in the demonstration laboratory. It will also be very interesting to have a webcam in the demonstration laboratory so that the visitors can ask questions directly to the person in the company. Of course, this type of agreement requires to be in contact with a person in charge of this demonstration in the company and to make sure that the visits fit his or her schedule. In the event this is not possible, there are alternative solutions like showing a video of the laser cutting process and of the employee telling facts about this application of lasers.

\section{CONCLUSION}

Designed and custom-built by members of Université Laval's OSA and SPIE Student Chapters at the COPL, the optical demonstration laboratory already contains a holography and a fiber optics set-up. Shortly, we are planning to add an adaptive optics set-up, an oxymeter, and to show live laser cutting work in a company.

Since its grand opening in October 2010, the demonstration laboratory has welcomed more than 800 visitors. Versatile and entertaining, this facility can accommodate visitors from various backgrounds in their discovery of the world of research in optics, and it allows graduate students to gain priceless experience in the creation and management of a research laboratory. It is also a precious tool to enhance the visibility of our field and our research center in our community.

\section{ACKNOWLEDGEMENTS}

The authors would like to thank Professor Réal Vallée for his support in this project and the COPL for lending the facilities for the demonstration laboratory. We would also like to thank the technicians who helped us put the lab together, design custom parts and sort out the electronics: Stephan Gagnon, Marc D'Auteuil, Patrick Larochelle and Philippe Chrétien, as well as Diane Déziel for her help with writing and proof-reading the various funding and grant requests. For the fiber optics and optical communications set-up, special thanks go to the work of Professor Younès Messadeq and Steeve Morency.

The demonstration laboratory has been funded by: SPIE, CorActive, INO, CIPI-S, Exfo, Cegep Garneau, Gentec-EO, Kentek, Sperian, NoIR Lasershields, Université Laval, Delta Photonics and CIPI. Finally, we would like to thank the Canadian Institute for Photonic Innovations for their generous funding which will allow us to put together the remaining demonstrations.

\section{REFERENCES}

[1] A.-S. Poulin-Girard et al., Photonic games: hands-on challenges to spark teenagers' interest in light, First Conference on Optics Education and Outreach, Proc. SPIE 7783, 77830A (2010);

[2] G. D. J. Harper, Holography project for the evil genius, McGraw-Hill Companies, 176 p. (2010).

[3] Integraf L.L.C. Holographic Film \& Supplies, http://www.integraf.com/ 